\title{
Identifikasi lansekap pura Negara Gambur Anglayang di Desa Kubutambahan, Kecamatan Kubutambahan, Kabupaten Buleleng
}

\author{
I Gede Bagus Reza Widiarsa Samba ${ }^{1}$, Cokorda Gede Alit Semarajaya ${ }^{1 *}$, I Nyoman Gede Astawa²
}

1. Program Studi Arsitektur Pertamanan, Fakultas Pertanian, Universitas Udayana, Indonesia

2. Program Studi Agroekoteknologi, Fakultas Pertanian, Universitas Udayana, Indonesia

*E-mail: coksemarajaya@unud.ac.id

\begin{abstract}
Identification of Negara Gambur Anglayang temple landscape on Kubutambahan Village, Kubutambahan Subdistrict, Buleleng Regency. Negara Gambur Anglayang Temple is one of the temples located in Kubutambahan Village, Buleleng Regency. There are some type of monument in this tample like monument Ratu Bagus Sundawan as an element Sunda, monument Ratu Agung Melayu as an element Melayu, monument Ratu Agung Syahbandar as an element China/Budha, monument Batara Surya, monument Ratu Pasek, monument Dewi Sri, monument Ratu Gede Siwa as an element Hindu/Bali, dan monument Ratu Gede Dalem Mekah as an element Islam. Identification of spatial pattern and forming elements of Negara Gambur Anglayang Temple is to find out whether the existence of various monument will influence the pattern of space used. The method used in this research is survey method, with data collection techniques is observation, interview, and literature. The results showed that the temple forming elements consisted of plants as soft elements and buildings as hard elements with their respective functions. The layout of the existing plants in the temple does not use the concept of Balinese cultural philosophy, and for the layout of the building using the concept of Balinese cultural philosophy that is hulu-teben. Spatial pattern used in Negara Gambur Anglayang Temple is Tri Mandala, where the part of yard is divided into three namely Nista Mandala, Madya Mandala and Utama Mandala.
\end{abstract}

Keywords: Negara Gambur Anglayang temple, Balinese cultural philosophy, spatial pattern

\section{Pendahuluan}

Bali merupakan salah satu provinsi di Indonesia yang memiliki beranekaragam budaya dan dihuni oleh penduduk yang beragam pula. Pulau Bali yang luasnya $5636,66 \mathrm{Km}^{2}$ memiliki jumlah penduduk 4.104 .900 jiwa, dan memeluk berbagai macam agama baik itu agama Hindu, Islam, Protestan, Katolik, Budha, dan juga Konghucu dengan persentase 91\% penduduknya memeluk agama Hindu dan 9\% penduduknya memeluk agama lain, yang artinya agama Hindu masih menjadi agama mayoritas yang dianut oleh penduduk Provinsi Bali (Badan Pusat Statistik Bali, 2015).

Pura Negara Gambur Anglayang adalah salah satu pura yang terdapat di Desa Pekraman Kubutambahan, Kecamatan Kubutambahan, Kabupaten Buleleng, yang memperlihatkan ciri mutikultural, terdapat delapan pelinggih yang mencerminkan unsur keberagaman. Masing-masing pelinggih mewakili unsurnya masing-masing, seperti Sunda, Melayu, Budha, Hindu, maupun Islam, yaitu pelinggih Ratu Bagus Sundawan sebagai unsur Sunda, pelinggih Ratu Bagus Melayu sebagai unsur Melayu, pelinggih Ratu Ayu Syahbandar sebagai unsur China/Budha, pelinggih Batara Surya, pelinggih Ratu Pasek, pelinggih Dewi Sri, pelinggih Ratu Gede Siwa sebagai unsur Hindu/Bali, dan pelinggih Ratu Gede Dalem Mekah sebagai unsur Islam. Uniknya kedelapan pelinggih ini berada dalam satu area tanpa adanya dinding pemisah antara pelinggih tersebut. (Widiarya, 2013). Suketama (2010) menyatakan, bahwa Pura Negara Gambur Anglayang awalnya merupakan pusat perdagangan yang dikelilingi oleh benteng yang disebut Kuta Banding (Benteng Perang), tempat seluruh pedagang baik dari suku, ras, dan agama yang berbeda-beda dari pulau-pulau lainnya berkumpul di sana melakukan transaksi. Tempat itu dipercaya bisa memberi mereka kehidupan, sehingga berbagai manusia berlainan keyakinan dan kepercayaan itu membangun sebuah pura. Pura ini merupakan lambang agama dipercaya sebagai satu tujuan manusia, dari manapun ia berasal.

Pola ruang merupakan susunan pusat ruang dengan bangunan dan halaman yang berfungsi sebagai pendukung kegiatan sosial budaya yang secara harfiah memiliki hubungan fungsional (Suarya, 2003). Pola 
ruang di Bali dibagi menjadi tiga, atau lebih dikenal dengan Tri Mandala. Tri Mandala terdiri dari Utama Mandala, Madya Mandala dan Nista Mandala. Dalam Tri Mandala pura termasuk ke dalam Utama Mandala. Identifikasi lansekap pura studi kasus: Pura Negara Gambur Anglayang sebagai simbol keberagaman menjadi sangat menarik dan unik sebagai topik penelitian, karena memiliki delapan pelinggih yang berbeda-beda, bukan hanya unsur Hindu, tetapi juga Islam, Budha, Sunda dan Melayu, sehingga patut diduga memiliki pola ruang dan elemen pembentuk ruang yang berbeda dari pura lainnya.

Berdasarkan dari latar belakang di atas maka permasalahan yang dapat diangkat dalam penelitian ini antara lain adalah: 1) Bagaimana pola ruang pada Pura Negara Gambur Anglayang?; 2) Apa saja elemen pembentuk ruang di Pura Negara Gambur Anglayang?. Sedangkan tujuan yang ingin dicapai dalam penelitian ini adalah untuk mengidentifikasi pola ruang pada Pura Negara Gambur Anglayang dan mengidentifikasi elemen pembentuk ruang yang ada di Pura Negara Gambur Anglayang.

\section{Metode Penelitian}

\subsection{Waktu dan Tempat Penelitian}

Penelitian dilaksanakan selama lima bulan mulai dari pengambilan data, analisis data, hingga penyusunan, dimulai dari bulan Maret sampai dengan bulan Juli 2017. Penelitian mengenai identifikasi Pura Negara Gambur Anglayang baik dari pola ruang dan elemen pembentuknya dilakukan di kawasan Pura Negara Gambur Anglayang dan sekitarnya yang terletak di Desa Pakraman Kubutambahan, Kecamatan Kubutambahan, Kabupaten Buleleng.

\section{$2.2 \quad$ Alat}

Alat yang digunakan untuk penelitian antara lain adalah kamera digital, alat perekam suara, lembar wawancara, perangkat lunak, AutoCAD 2016.

\subsection{Metode Penelitian}

Metode penelitian yang digunakan adalah metode survei (Sugiyono, 2010), dengan teknik pengumpulan data yang digunakan dalam penelitian ini sebagai berikut:

a. Observasi atau pengamatan langsung ke Pura Negara Gambur Anglayang di desa Kubutambahan untuk mengumpulkan data aksesibilitas, mengukur luas area pura, mengamati pola dan elemen pura dan mendokumentasikannya.

b. Wawancara, merupakan teknik pengumpulan data yang digunakan untuk memperoleh informasi yang lebih mendalam dengan mengadakan tanya jawab langsung dengan Bapak Nyoman Laken selaku pengelola Pura Negara Gambur Anglayang untuk mengetahui batas wilayah, fungsi elemen lansekap, pengelola pura, pengguna ruang dan pola ruang yang digunakan di Pura Negara Gambur Anglayang.

c. Studi Pustaka, yaitu mencari data-data yang berhubungan dengan penelitian baik melalui buku-buku, refrensi, jurnal maupun media internet. Data yang terkumpul dianalisis secara deskriptif (disajikan pada Tabel 1).

Tabel 1. Jenis Data, Sumber Data, Pengambilan Data

\begin{tabular}{|c|c|c|c|c|}
\hline \multirow{2}{*}{ No } & \multirow{2}{*}{ Data } & \multicolumn{2}{|c|}{ Jenis Data } & \multirow{2}{*}{ Sumber Data } \\
\hline & & Primer & Sekunder & \\
\hline \multirow[t]{8}{*}{1.} & Aspek Biofisik & & & \\
\hline & a. Luas Tapak & Primer & & Wawancara dan Observasi \\
\hline & b. Pengguna Ruang & Primer & & Wawancara \\
\hline & c. Aksesibilitas & Primer & & Observasi \\
\hline & d. Elemen Lansekap & Primer & & Wawancara dan Observasi \\
\hline & $\begin{array}{l}\text { e. Tata Letak Elemen } \\
\text { Lansekap }\end{array}$ & Primer & Sekunder & Observasi dan Studi Pustaka \\
\hline & $\begin{array}{ll}\text { f. } & \text { Fungsi Elemen } \\
\text { Lansekap }\end{array}$ & Primer & Sekunder & $\begin{array}{l}\text { Wawancara dan Studi Pustaka } \\
\text { Wawancara, Observasi dan Studi }\end{array}$ \\
\hline & g. Pola Ruang & Primer & Sekunder & Pustaka \\
\hline \multirow[t]{3}{*}{2.} & Aspek Sosekbud & & & \\
\hline & a. Jumlah Penduduk & Primer & Sekunder & Studi Pustaka dan Observasi \\
\hline & $\begin{array}{l}\text { b. Sosial, Ekonomi } \\
\text { Penduduk }\end{array}$ & Primer & Sekunder & \\
\hline
\end{tabular}




\subsubsection{Analisis Data}

Hasil data yang telah dikumpulkan kemudian ditabulasi dan dianalisis secara deskriptif (Sugiyono, 2004). Selanjutnya dilakukan tahap sintesis dari hasil penelitian ini, berupa Identifikasi pola ruang dan elemen pembentuk di Pura Negara Gambur Anglayang sebagai simbol keberagaman.

\subsection{Batasan Penelitian}

Penelitian ini dilakukan di kawasan lansekap Pura Negara Gambur Anglayang dengan ruang lingkup pola ruang yang diterapkan dan elemen pembentuknya, baik berisi tata letak serta fungsi elemen lunak dan elemen keras. Tahap studi dilakukan dengan pengumpulan data, analisis, dan simpulan.

\section{Hasil dan Pembahasan}

\subsection{Gambaran Umum Pura Negara Gambur Anglayang}

Pura Negara Gambur Anglayang terletak di Banjar Adat Kuta Banding, Desa Pekraman Kubutambahan, Kecamatan Kubutambahan, Kabupaten Buleleng. Pura Negara Gambur Anglayang memiliki arti yaitu pura berarti tempat ibadah atau melakukan persembahyangan, Negara berarti Negara, Gambur berarti suara genta/bajra, Anglayang berarti mengudara, jadi artinya pura yang mengeluarkan suara genta/bajra yang mengudara hingga terdengar ke seluruh Negara. Pura Negara Gambur Anglayang terletak di pinggir Pantai Kuta Banding, dengan jarak $100 \mathrm{~m}$ dari bibir pantai dan memiliki luas tapak $1.300 \mathrm{~m}^{2}$.

Pura Negara Gambur Anglayang dikelola oleh Pengempon, Pengemong, Penyiwi, Pengempon adalah mereka yang memimpin dan memberi tugas untuk melakukan upacara tetap dan pembinaan pura. Pengemong/krama adalah masyarakat atau desa terdekat dengan pura yang merupakan tenaga pelaksanapelaksana upacara dan perawatan pura dikoordinir oleh pengempon. Penyiwi adalah masyarakat luar yang melakukan pemujaan di pura tersebut. Jumlah kramalanggota berjumlah 525 orang yang terdiri dari semua masyarakat desa Kubutambahan dan semuanya beragama Hindu.

\subsection{Sejarah Pura Negara Gambur Anglayang}

Menurut Penelitian Widiarya (2013), terkait dengan kondisi perekonomian hubungan dagang sangat lancar maka pada suatu saat terkisah sebuah Perahu dengan beberapa penumpang dengan bermacam etnis (suku) bersandar dipantai Kuta Banding. Adapun tujuan perahu dagang tersebut yaitu untuk mencari bahanbahan dagangan di samping mencari kebutuhan konsumsi makanan, air dan yang sejenisnya. Setelah mendapatkan kebutuhan (bahan dagangan dan konsumsi), maka awak kapal bersiap-siap untuk melanjutkan perjalanan ketempat tujuan, namun terjadi sebuah musibah, perahu mengalami kebocoran, sehingga tidak bisa berangkat. Kemudian para awak kapal dibantu oleh penduduk setempat berusaha memperbaiki kapal yang bocor, akan tetapi tidak berhasil. Akibat dari kegagalan tersebut, penduduk setempat mengajak awak kapal beserta rombongan kapal untuk melakukan persembahyangan bersama di pelinggih pesisir Kuta Banding. Bila perjalanannya selamat dan usahanya ataupun karirnya sukses mereka berikrar atau sudi mengakui, percaya dan yakin serta ikut mengagungkan serta memelihara tempat yang disucikan untuk memuja kebesaran Shang Hyang Widhi dengan Prabawa (manifestasi) sebagai Siwa.

Berdasarkan semua itu sebagai wujud terima kasih atas segala jasa baik berupa pengetahuan dagang, pengetahuan bertani, nelayan termasuk pengetahuan keprajuritan, maka atas dasar komitmen secara moral, dibangunlah suatu monumen peringatan (miniatur yang disucikan) berupa pelinggih-pelinggih sederhana. Pelinggih ini dilengkapi dengan suatu perwujudan sesuai dengan imajinasi masyarakat sesuai dengan undagiundaginya di samping pelinggih pokok, yaitu Dewa Siwa.

\subsection{Pola Ruang Pura Negara Gambur Anglayang}

Menurut hasil wawancara dengan Gede Suma (2017) selaku Pengempon Klian Pura di Pura Negara Gambur Anglayang, pura ini memakai konsep tata ruang yaitu Tri Mandala, yang dibagi menjadi tiga halaman yakni jaba sisi atau nista mandala sebagai simbol bhur loka, jaba tengah atau madya mandala sebagai simbol bwah loka dan jeroan atau utama mandala sebagai simbol swah loka. Secara lebih khusus, pola ruang Pura Negara Gambur Anglayang meliputi: jenis dan elemen pembentuk dan tata letak elemen pembentuk pura. Pola tata ruang Pura Negara Gambur Anglayang dilihat pada Gambar 1. 


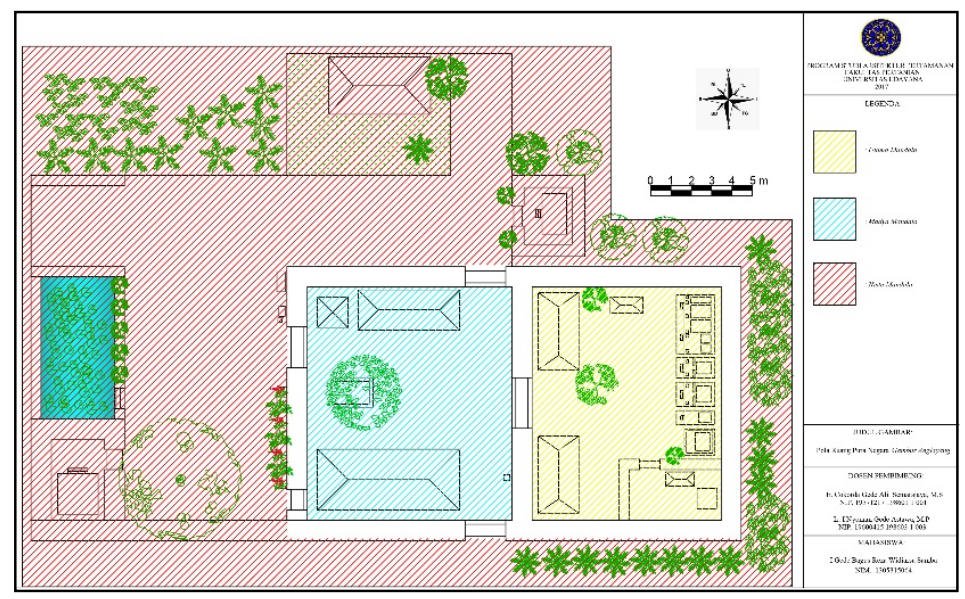

Gambar 1. Pola Tata Ruang di Pura Negara Gambur Anglayang

\subsection{Jenis dan Fungsi Elemen Pembentuk Pura Negara Gambur Anglayang}

3.4.1 Jenis dan Fungsi Tanaman (elemen lunak)

Adapun jenis, fungsi dan kondisi tanaman di Pura Negara Gambur Anglayang dapat dilihat pada Tabel 2.

Tabel 2. Jenis, Fungsi dan Kondisi Tanaman di Pura Negara Gambur Anglayang

\begin{tabular}{|c|c|c|c|c|}
\hline No & Jenis Tanaman & Jumlah & Fungsi dalam Lansekap & Kondisi \\
\hline 1 & $\begin{array}{l}\text { Kelapa } \\
\text { (Cocos nucifera) }\end{array}$ & 12 & $\begin{array}{l}\text { Digunakan sebagai prasarana } \\
\text { persembahyangan }\end{array}$ & $\begin{array}{l}\text { Tumbuh di nista mandala } \\
\text { sebelah selatan dan } \\
\text { timur }\end{array}$ \\
\hline 2 & $\begin{array}{l}\text { Pohon jati } \\
\text { (Tectona grandis) }\end{array}$ & 3 & Sebagai peneduh & Tumbuh di nista mandala \\
\hline 3 & $\begin{array}{l}\text { Palem segitiga } \\
\text { (Dypsis decaryi) }\end{array}$ & 10 & Sebagai pembatas fisik & $\begin{array}{l}\text { Tumbuh liar di nista } \\
\text { mandala }\end{array}$ \\
\hline 4 & Bambu (Bambusa Sp) & 6 & Sebagai control pandangan & $\begin{array}{l}\text { Tumbuh liar di nista } \\
\text { mandala }\end{array}$ \\
\hline 5 & Lengkuas (Alpinia Sp) & 20 & Sebagai pembatas fisik & $\begin{array}{l}\text { Tumbuh liar di nista } \\
\text { mandala }\end{array}$ \\
\hline 6 & $\begin{array}{l}\text { Pohon asam } \\
\text { (Tamarindus indicia) }\end{array}$ & 2 & Sebagai peneduh & $\begin{array}{l}\text { Tumbuh liar di nista } \\
\text { mandala }\end{array}$ \\
\hline 7 & $\begin{array}{l}\text { Kamboja } \\
\text { (Plumeria Sp) }\end{array}$ & 8 & $\begin{array}{l}\text { Sebagai peneduh saat } \\
\text { bersembahyang dan } \\
\text { bunganya digunakan sebagai } \\
\text { sarana persembahyangan }\end{array}$ & $\begin{array}{l}\text { Tumbuh baik di utama } \\
\text { mandala dan nista } \\
\text { mandala sebelah kolam }\end{array}$ \\
\hline 8 & $\begin{array}{l}\text { Beringin } \\
\text { (Ficus benjamina) }\end{array}$ & 1 & Sebagai peneduh & $\begin{array}{l}\text { Tumbuh dengan rindang } \\
\text { di nista mandala }\end{array}$ \\
\hline 9 & Teratai (Nymphaea) & 7 & Sebagai estetika Kolam & Tumbuh baik di kolam \\
\hline 10 & $\begin{array}{l}\text { Adam hawa } \\
\text { (Rhoeo spathacea) }\end{array}$ & 2 & $\begin{array}{l}\text { Sebagai estetika di sekitar } \\
\text { pohon beras }\end{array}$ & $\begin{array}{l}\text { Tumbuh baik di dalam } \\
\text { pot sekitar pohon beras }\end{array}$ \\
\hline 11 & Soka (Ixora L.) & 4 & Sebagai estetika & $\begin{array}{l}\text { Tumbuh baik di taman } \\
\text { depan pura }\end{array}$ \\
\hline 12 & $\begin{array}{l}\text { Nusa indah } \\
\text { (Mussaenda pubescens) }\end{array}$ & 3 & Sebagai estetika & $\begin{array}{l}\text { Tumbuh baik di taman } \\
\text { depan pura }\end{array}$ \\
\hline 13 & $\begin{array}{l}\text { Pohon beras } \\
\text { (Hibiscus tiliaceus) }\end{array}$ & 1 & Sebagai tempat pemujaan & $\begin{array}{l}\text { Tumbuh rindang di } \\
\text { madya mandala }\end{array}$ \\
\hline
\end{tabular}

3.4.2 Jenis dan Fungsi Bangunan (elemen keras) 
Menurut Gelebet, dkk (2002), dalam suatu pura terdapat tiga jenis bangunan menurut fungsinya yaitu bangunan utama, bangunan pelengkap, dan bangunan penyempurna. Bangungan utama adalah bangunanbangunan pelinggih untuk perwujudan (menstanakan) yang dipuja atau diupacarai di pura tersebut. Bangunan pelengkap adalah bangungan-bangunan yang melengkapi untuk melaksanakan upakara, Bale Gong, Bale Pebat, Bale Pesandek Penghulu, Bale Petanding, Bale Piasan merupakan bangunan-bangunan pelengkap. Bangunan penyempurna sebagai bangunan tambahan yang menyempurnakan suatu pura, candi bentar, kori agung, bale kulkul, kamar mandi dan area parkir merupakan pelengkap yang menyempurnakan Pura Negara Gambur Anglayang. Bangunan- bangunan tersebut memiliki fungsi dan kondisinya masing-masing, disajikan dalam Tabel 3.

Tabel 3. Fungsi dan Kondisi Masing-masing dari Bangunan di Pura Negara Gambur Anglayang

\begin{tabular}{|c|c|c|c|}
\hline No & Nama Bangunan & Fungsi Bangunan & Kondisi \\
\hline 1 & Kamar Mandi & $\begin{array}{l}\text { Sebagai tempat buang air bagi } \\
\text { pengunjung maupun pengelola }\end{array}$ & $\begin{array}{l}\text { Baik dan masih } \\
\text { berfungsi }\end{array}$ \\
\hline 2 & Area Parkir & $\begin{array}{l}\text { Sebagai tempat parkir kendaraan } \\
\text { pengunjung dan pengelola }\end{array}$ & $\begin{array}{l}\text { Meminjam lahan } \\
\text { warga }\end{array}$ \\
\hline 3 & Pelinggih Ratu Ayu Taman & $\begin{array}{l}\text { Dipercaya sebagai pelabuhan secara } \\
\text { niskala }\end{array}$ & Baik \\
\hline 4 & Puncakin Tirtha & $\begin{array}{l}\text { Sebagai tempat mengambil tirta dan } \\
\text { sumber air }\end{array}$ & Baik \\
\hline 5 & $\begin{array}{l}\text { Pelinggih Ratu Gede Mas } \\
\text { Penggawa }\end{array}$ & $\begin{array}{l}\text { Sebagai penjaga atau pengaman, } \\
\text { pertama kali harus bersembahyang } \\
\text { disini }\end{array}$ & Baik \\
\hline 6 & Candi Bentar & $\begin{array}{l}\text { Dinding pemisah antara halaman luar } \\
\text { dan halaman tengah }\end{array}$ & Baik \\
\hline 7 & Bale Kulkul & $\begin{array}{l}\text { Sebagai alat untuk memanggil dan } \\
\text { mengumpulkan semeton atau warga }\end{array}$ & $\begin{array}{l}\text { Baik dan masih } \\
\text { berfungsi }\end{array}$ \\
\hline 8 & Bale Pebat & $\begin{array}{l}\text { Tempat untuk mebat dan tempat untuk } \\
\text { menyediakan makanan maupun } \\
\text { minuman }\end{array}$ & Baik \\
\hline 9 & Bale Gong & Tempat untuk penabuh gamelan & Baik \\
\hline 10 & $\begin{array}{l}\text { Candi Kurung atau Kori } \\
\text { Agung }\end{array}$ & $\begin{array}{l}\text { Dinding pemisah halaman tengah dan } \\
\text { halaman dalam }\end{array}$ & Kurang direnovasi \\
\hline 11 & Bale Pesandek Penghulu & $\begin{array}{l}\text { Tempat beristirahat para pemangku } \\
\text { dan pengurus pura }\end{array}$ & Baik \\
\hline 12 & Bale Petanding & Sebagai tempat menyiapkan canang & Baik \\
\hline 13 & Bale Piyasan Agung dan Alit & $\begin{array}{l}\text { Tempat untuk pemujaan terhadap } \\
\text { Batara dan juga tempat untuk orang } \\
\text { suci }\end{array}$ & Baik \\
\hline 14 & $\begin{array}{l}\text { Pelinggih Ratu Bagus } \\
\text { Sundawan }\end{array}$ & Mewakili unsur Sunda & Baik \\
\hline 15 & $\begin{array}{l}\text { Pelinggih Ratu Agung } \\
\text { Melayu }\end{array}$ & Mewaliki unsur Melayu & Baik \\
\hline 16 & $\begin{array}{l}\text { Pelinggih Ratu Agung } \\
\text { Syahbandar }\end{array}$ & Mewakili unsur China/Buddha & Baik \\
\hline 17 & Pelinggih Batara Surya & Mewakili unsur Bali/Hindu & Baik \\
\hline 18 & Pelinggih Ratu Pasek & Mewakili unsur Bali/Hindu & Baik \\
\hline 19 & Pelinggih Dewi Sri & Mewakili unsur Bali/Hindu & Baik \\
\hline 20 & Pelinggih Ratu Gede Siwa & Mewakili unsur Bali/Hindu & Baik \\
\hline 21 & $\begin{array}{l}\text { Pelinggih Ratu Gede Dalem } \\
\text { Mekah }\end{array}$ & Mewakili unsur Islam & Baik \\
\hline 22 & $\begin{array}{l}\text { Pelinggih Ratu Ayu Muterin } \\
\text { Jagat }\end{array}$ & Mewakili unsur Bali/Hindu & Baik \\
\hline
\end{tabular}




\subsection{Pola Tata Letak Elemen Pembentuk Pura Negara Gambur Anglayang}

\subsubsection{Pola Tata Letak Tanaman (elemen lunak)}

Penelitian ini menunjukkan bahwa di Pura Negara Gambur Anglayang tanaman diletakkan tidak menggunakan konsep Asta Dala sesuai filosofi budaya Bali, tetapi di letakkan pada tiga bagian yaitu Utama Mandala, Madya Mandala, dan Nista Mandala, denah tanaman di Pura Negara Gambur Anglayang dapat dilihat pada Gambar 2.

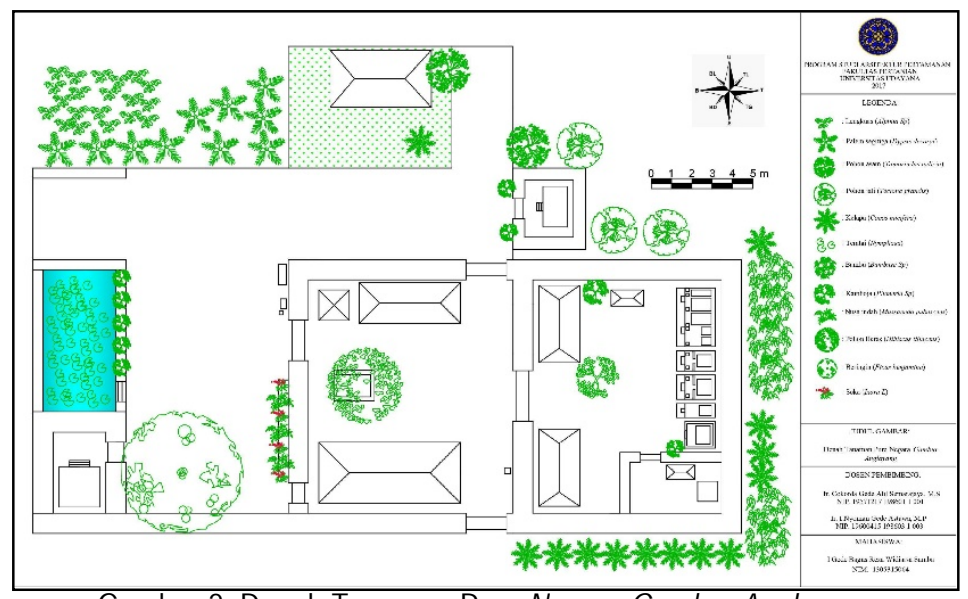

Gambar 2. Denah Tanaman Pura Negara Gambur Anglayang

\subsubsection{Pola Tata Letak Bangunan (elemen keras)}

Penelitian ini menunjukkan, meskipun Pura Negara Gambur Anglayang memiliki pelinggih yang mewakili tidak hanya unsur Bali/Hindu saja, pura ini tetap menggunakan konsep filosofi budaya Bali yaitu konsep Tri Mandala dan Hulu-teben, dengan bagian hulu sebagai tempat paling utama letaknya di Uttara atau Timur, dan teben sebagai tempat kotor yang letaknya di arah Selatan maupun Barat, tetapi untuk daerah Buleleng, orientasi berdasarkan sumbu religi, yaitu arah Uttara-Selatan (kaja-kelod) berbeda dengan daerah lainnya di Bali, dikarenakan untuk daerah Buleleng gunung sebagai tempat paling suci berada di kaja (selatan untuk daerah Buleleng), dan laut berada di kelod (utara untuk daerah Buleleng) sehingga kaja-kelod di Buleleng terbalik dengan daerah lainnya. Pura Negara Gambur Anglayang mengikuti orientasi tersebut, sehingga untuk bangunan pelinggih diletakkan di arah Selatan dan Timur menurut mata angin, dan untuk orientasi sumbu religi dan sumbu bumi menggunakan kaja-kangin sesuai filosofi budaya Bali, denah Pura Negara Gambur Anglayang dapat dilihat pada Gambar 3.

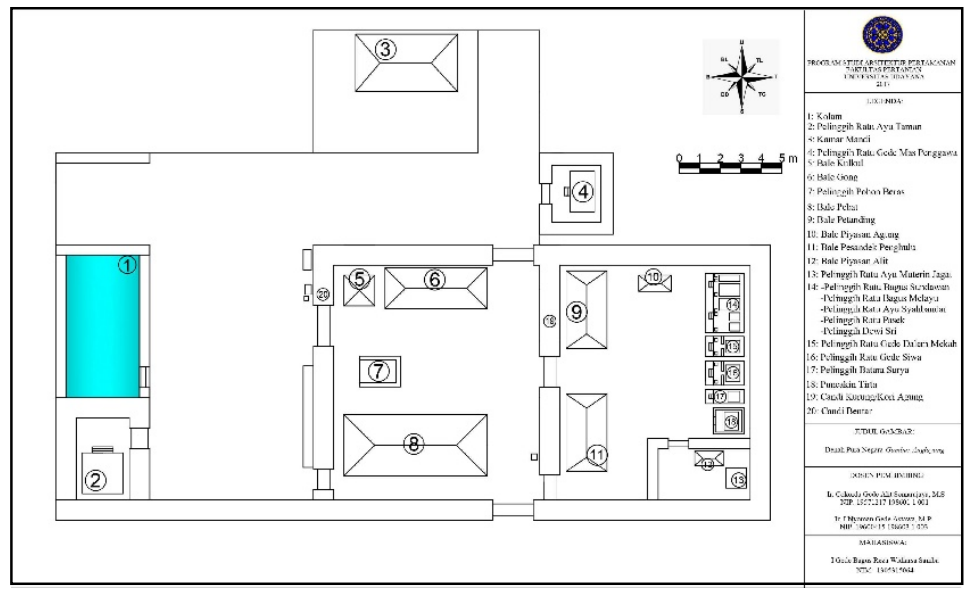

Gambar 3. Denah Pura Negara Gambur Anglayang

\subsection{Rekomendasi Penempatan Tanaman Berdasarkan Konsep Filosofi Budaya Bali}

Tata letak tanaman (elemen lunak) belum sesuai dengan konsep filosofi budaya Bali, yaitu konsep Asta Dala, sehingga rekomendi yang diberikan yaitu peletakan tanaman dengan konsep Asta Dala sebagai konsep folosofi budaya Bali, dengan menggunakan tanaman yang memiliki warna baik dari daun, batang, dan 
bunga sesuai dengan arah mata angin, tetapi hanya menggunakan empat arah mata angin saja yaitu utara berwarna hitam, timur berwarna putih, selatan berwarna merah, dan barat berwarna kuning, disajikan pada Table 4 dan gambar pada Gambar 4.

Tabel 4. Tanaman yang akan ditanam di Area Pura

\begin{tabular}{|c|c|c|c|c|}
\hline \multirow{2}{*}{\multicolumn{5}{|c|}{ Fungsi dalam Lansekap }} \\
\hline & & & & \\
\hline 1 & $\begin{array}{l}\text { Gandaria } \\
\text { (Bouea macrophylla) }\end{array}$ & $\begin{array}{l}\text { Kuning } \\
\text { (Buah) }\end{array}$ & Barat & Sebagai Pembatas \\
\hline 2 & $\begin{array}{l}\text { Kenanga } \\
\text { (Cananga odorata) }\end{array}$ & $\begin{array}{l}\text { Kuning } \\
\text { (Bunga) }\end{array}$ & Barat & Sarana Upakara \\
\hline 3 & Kelapa (Cocos nucifera) & $\begin{array}{l}\text { Kuning } \\
\text { (Buah) }\end{array}$ & Barat & $\begin{array}{l}\text { Digunakan sebagai prasarana } \\
\text { Upakara }\end{array}$ \\
\hline 4 & $\begin{array}{l}\text { Kembang merak } \\
\text { (Caesalpinia } \\
\text { pulcherrima L.) }\end{array}$ & $\begin{array}{l}\text { Merah } \\
\text { (Bunga) }\end{array}$ & Selatan & $\begin{array}{l}\text { Sebagai Kontrol Pandangan } \\
\text { dan Estetika }\end{array}$ \\
\hline 5 & $\begin{array}{l}\text { Kembang sepatu } \\
\text { (Hibiscus rosasinensis) }\end{array}$ & $\begin{array}{l}\text { Merah } \\
\text { (Bunga) }\end{array}$ & Selatan & $\begin{array}{l}\text { Sebagai Kontrol Pandangan } \\
\text { dan Estetika }\end{array}$ \\
\hline 6 & $\begin{array}{l}\text { Nibung } \\
\text { (Oncosperma tigillarium) }\end{array}$ & $\begin{array}{l}\text { Hitam } \\
\text { (Batang) }\end{array}$ & Utara & Sebagai Pembatas \\
\hline 7 & $\begin{array}{l}\text { Pohon asam } \\
\text { (Tamarindus indicia) }\end{array}$ & $\begin{array}{c}\text { Hitam } \\
\text { (Tajuknya) }\end{array}$ & Utara & Sebagai Peneduh \\
\hline 8 & $\begin{array}{l}\text { Palem waregu } \\
\text { (Rhapis flabelliformis) }\end{array}$ & $\begin{array}{l}\text { Hitam } \\
\text { (Batang) }\end{array}$ & Utara & Sebagai Pembatas \\
\hline 9 & Mangga (Mangifera Indica) & $\begin{array}{l}\text { Hitam } \\
\text { (Tajuknya) }\end{array}$ & Utara & Sebagai Peneduh \\
\hline 10 & Kamboja (Plumeria Sp) & $\begin{array}{l}\text { Putih } \\
\text { (Bunga) }\end{array}$ & Timur & $\begin{array}{l}\text { Sebagai Kontrol Pandangan, } \\
\text { sarana Upakara }\end{array}$ \\
\hline 11 & $\begin{array}{l}\text { Cempaka putih } \\
\text { (Michelia alba) }\end{array}$ & $\begin{array}{l}\text { Putih } \\
\text { (Bunga) }\end{array}$ & Timur & $\begin{array}{l}\text { Sebagai Kontrol Pandangan, } \\
\text { sarana Upakara }\end{array}$ \\
\hline
\end{tabular}

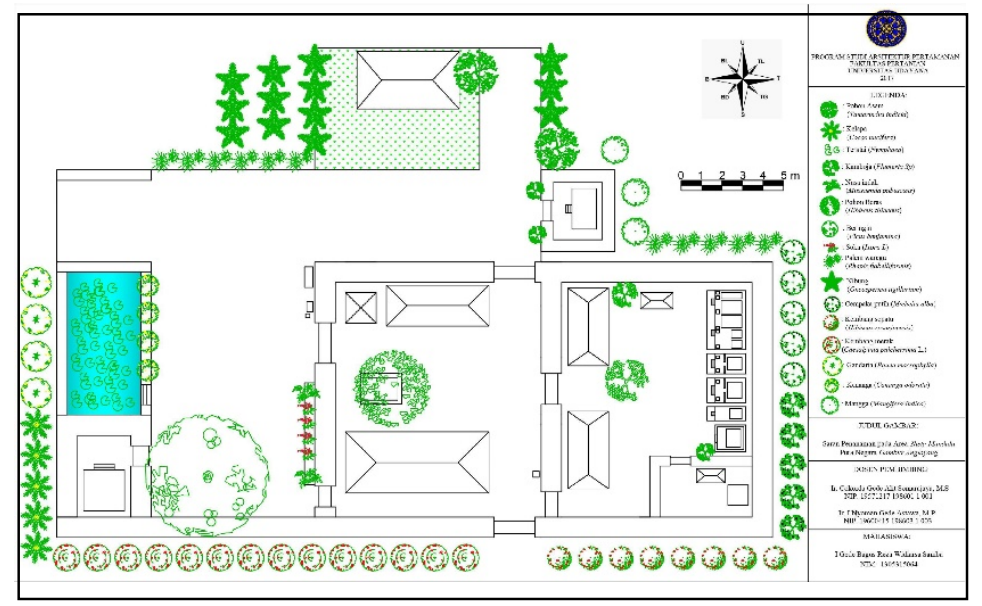

Gambar 4. Rekomendasi Penempatan Tanaman pada Area Nista Mandala Pura Negara Gambur Anglayang

\section{Simpulan Dan Saran \\ 4.1 Simpulan}

Berdasarkan hasil penelitian dapat disimpulkan, bahwa Pura Negara Gambur Anglayang memiliki pola ruang dan elemen pembentuk sebagai berikut:

1. Pura Negara Gambur Anglayang memiliki pola ruang yang menggunakan filososi budaya Bali, meskipun disana terdapat pelinggih yang tidak hanya mengandung unsur Bali/Hindu. Pola ruang yang digunakan yaitu Tri Mandala dengan pembagian ruang Nista Mandala, Madya Mandala, dan Utama 
Mandala, dengan konsep tata letak bangunan menggunakan konsep hulu-teben, yang hulu sebagai tempat utama, dan teben sebagai tempat kotor. Perbedaan orientasi kaja-kelod di buleleng mempengaruhi peletakan pelinggih di pura ini, sedangkan untuk tata letak tanaman Pura Negara Gambur Anglayang tidak menggunakan konsep apapun.

2. Elemen pembentuk ruang yang ada di Pura Negara Gambur Anglayang ada dua yaitu tanaman sebagai elemen lunak dan bangunan sebagai elemen keras. Tanaman banyak terdapat pada area Nista Mandala, sedangkan untuk bangunan, dibagi sesuai fungsinya yaitu sebagai bangunan utama (pelinggih) terdapat pada area Utama Mandala, bangunan pelengkap pada area Madya Mandala, dan bangunan penyempurna berada di Nista Mandala.

\subsection{Saran}

Berdasarkan hasil penelitian tersebut maka saran yang diberikan adalah rekomendasi penempatan tanaman pada area Pura Negara Gambur Anglayang dapat dijadikan masukan dan pertimbangan dalam melakukan perbaikan terutama dalam penanaman pada area Nista Mandala pura ini, agar terlihat lebih baik lagi dalam keberagamannya dari segi tanaman dan menggunakan konsep filosofi budaya Bali.

\section{Daftar Pustaka}

Badan Pusat Statistik Bali. 2015. Badan Pusat Statistik Provinsi Bali. Available online at: http://bali.bps.go.id/. (Accessed 29 September 2016).

Gelebet, I N. ; I W. Meganada; I M. Y. Negara; I M. Suwirya; I N. Surata; 2002. Arsitektur Tradisional Daerah Bali. Milik Badan Pengembangan Kebudayaan dan Pariwisata, Bali, Denpasar. Hal 126.

Suarya, I M. 2003. Peranan Natah di Dalam Kehidupan Masyarakat Bali. Jurnal. Fakultas Teknik. Universitas Udayana. Denpasar. Hal 21.

Sugiyono. 2010. Metode Penelitian Kuantitatif, Kualitatif dan R\&D. Alfabeta. Bandung. Hal 10.

Sugiyono, 2004. Metode Penelitian Bisnis. CV. Alfabeta. Bandung. Hal 10.

Suketama, K. 2010. Pura Negara Gambur Anglayang Desa Pakraman Kubutambahan, Kecamatan Kubutambahan, Kabupaten Buleleng. Bali Post. Bali. Hal 5-10.

Widiarya, G. 2013. Pura Negara Gambur Anglayang di Desa Pakraman Kubutambahan, Buleleng, Bali (Sejarah, Struktur, dan Potensinya Sebagai Media Pendidikan Multikultural bagi Masyarakat Sekitarnya). Jurnal. Jurusan Pendidikan Sejarah. Universitas Pendidikan Ganesha. Hal 7-10.

Narasumber: Gede Suma. 2017. 